\title{
Defining trajectories of acute pain in surgical patients short title: acute pain follow-up
}

\author{
(iD) Paola Lecompte ${ }^{1}$ \\ (iD) Daniel Benitez ${ }^{1}$ \\ (iD) Jairo Moyano ${ }^{1}$ \\ DClaudia Quiroga Garzon ${ }^{2}$
}

1. Department of Anaesthesia University Hospital Fundación SantaFe de Bogota, Colombia 2. Department of Anaesthesiology, University El Rosario Bogotá, Colombia

http://dx.doi.org/10.1590/1806-9282.65.6.825

\section{SUMMARY}

INTRODUCTION: Assessment of acute postoperative pain is mandatory for effective treatments. Pain trajectories may help professionals improve treatments. It has been suggested that uncontrolled pain in the immediate postoperative period generates higher pain intensities on the following days of hospital stay.

OBJECTIVE: To determine the relationship between pain during the first postoperative hour and the first 24 postoperative hours.

METHODS: Setting: a general university hospital. Study design: a prospective observational, analytical study of patients undergoing surgical procedures under general anesthesia and hospitalized for at least 24 hours. Five assessments of pain were carried out during the first hour in the recovery room followed by three assessments during the first 24 hours. The slopes of pain trajectories were calculated, and the relationship between them was analyzed.

RESULTS: 234 patients were recruited, 37.3\% had uncontrolled pain on arrival at the recovery room; at the end of the first 24 hours after surgery, 5.5\% of the patients had uncontrolled pain. The first pain intensity score in the recovery room correlated negatively with the slope for the first hour (P7): rS =-0.657 ( $p=0.000)$. Similarly, the first pain intensity score had a negative association with the pain trajectory slope during the hospital stay (P2): $r S=-0.141$ ( $p=0.032$ ). When comparing the two slopes, a nonsignificant negative correlation was found: $r S=-0.126$.

CONCLUSIONS: the trajectory of pain during the first hour does not predict the behavior of the trajectory during the first day after surgery. KEYWORDS: Postoperative pain. Pain measurement. Pain management. Acute pain.

\section{INTRODUCTION}

Competent acute postoperative pain treatment has noteworthy physiological and psychological benefits, such as early feeding and mobilization, reduced pulmonary and cardiovascular morbidity, and relieved suffering ${ }^{1-5}$; in other words, proper pain relief is an important outcome of surgery. Therefore, monitoring pain intensity and its relief over time is a valuable postoperative care measure. The control of pain intensity on arrival at the post-anesthesia care unit
(PACU) is essential in order to obtain a successful hospital transit, ${ }^{6}$ and it has been identified as a predictor of severe postoperative pain ${ }^{7,8}$. It is important to realize that the measure of the intensity of pain at a single time excludes the changing course of postoperative pain over time, so the buildup of trajectories of pain can help understand individual patients ${ }^{9}$. A trajectory is a path or line of development, hence the influence of the trajectory of pain intensity during

DATE OF SUBMISSION: 27-Aug-2018

DATE OF ACCEPTANCE: 09-Jan-2019

CORRESPONDING AUTHOR: Jairo Moyano

Pain Service, Department of Anaesthesia, Fundación SantaFe de Bogotá, El Bosque University

Address: Cra 7 n$^{\circ} 117-15$, Bogota, Colombia

E-mail: jmoyano@unibosque.edu.co 
the first hour could predict the intensity during the next few hours after surgery. The objective of this study is to explore the relationship between pain intensity in the first postoperative hour and the intensity of pain during the first 24 hours. We hypothesize that the trajectory of pain intensity during the first hour after surgery directly affects the trajectory of pain intensity during the first postoperative day.

\section{MATERIALS AND METHODS}

A prospective observational, analytical study was conducted at a single university hospital that performs 14,500 anesthetic procedures per year. Approval was requested from the Institutional Ethics Committee, which decided there was no need for informed consent. All adult patients subjected to surgical procedures under general anesthesia and hospitalized for at least 24 hours were included. The study period was 14 consecutive months. The following patients were excluded: those discharged to the Intensive Care Unit, those with a severe preoperative cognitive deficit or uncontrolled psychiatric illness, those who were unable to communicate, obstetric and pediatric patients, and patients treated by the Acute Pain Service.

The anesthetic technique was determined by the attending anesthesiologist and was mostly based on propofol $(1-2 \mathrm{mg} / \mathrm{kg})$, rocuronium bromide $(0.5 \mathrm{mg} /$ $\mathrm{kg})$, remifentanil $(0.1-0.3 \mathrm{mcg} / \mathrm{kg} / \mathrm{min})$, and subMAC concentrations of inhaled agent (sevoflurane or desflurane) according to BIS readings, paracetamol (1 gram) or diclofenac $(1 \mathrm{mg} / \mathrm{kg})$ were administered intravenously during induction of anesthesia. By the end of surgery, all patients had received an intravenous loading dose of opioid (morphine or hydromorphone) equivalent to $0.15 \mathrm{mg} / \mathrm{kg}$ of morphine. Once the patient had been extubated and obtained a Ramsay sedation score of 2 , they were transferred to the Post-Anesthetic Care Unit (PACU) where the pain assessment was as follows: on arrival (t0), after 15 $\min (\mathrm{t} 1)$, after $30 \mathrm{~min}(\mathrm{t} 2)$, after $45 \mathrm{~min}$ (t3) and after 60 minutes ( $\mathrm{t} 4)$. Three assessments were carried out after the patient had been transferred to the hospital ward: on arrival (t5), after 12 hours (t6) and after 24 hours (t7). Staff members of the Anesthesia Department carried out the assessments by using the Verbal Rating Scale $($ VRS $)(0=$ no pain and $10=$ the worst imaginable pain).

Demographic variables, type of surgery, ASA clas- sification status, pain intensity at different times, the doses of intraoperative morphine plus titration in the PACU and the equianalgesic doses of morphine during the first 24 hours of hospitalization were analyzed. Based on each patient's pain intensity, the individual slope of the first hour's trajectory (P1) was calculated using to to $t 4$ pain scores and the slope for the first 24 hours (P2) by using t5 to 7 pain scores. Mild pain was defined as VRS $\leq 3 / 10$, and severe/ unbearable pain was defined as VRS $\geq 7 / 10$. Positive slopes meant worsening of pain, and negative slopes meant improved pain over time.

\section{STATISTICAL ANALYSIS}

To calculate the sample size, the average number of surgical procedures per month was taken from the institutional data $(\mathrm{n}=1138)$; about $75 \%(\mathrm{n}=853)$ of those were performed under general anesthesia, and of these approximately $55 \%(n=426)$ were on an outpatient basis. It was estimated that a sample size of 234 patients would provide $80 \%$ of power to detect differences between slopes, with a $95 \%$ confidence level; the analysis was performed to two queues. Patients were classified as decreasing or increasing in pain over time. Frequencies and percentages analyzed the nominal variables. For the quantitative variables, averages and standard deviations (SDs) were calculated, and if they were asymmetrical, the median and percentiles were calculated. The statistical tests were carried out using the software SPSS Statistics 22, and Spearman's correlation coefficient (rS) was used to determine the association between variables. Individual slopes of the first postoperative hour (P1) and the slopes of the first 24 postoperative hours (P2) were compared.

\section{RESULTS}

A total of 234 patients were included; their ages ranged between 18 and 88 years, with an average of 50 years, and $59 \%(n=138)$ were female. The mean intensity on arrival at the PACU was $4.5 / 10$, with $40.6 \%(n=95)$ of the patients reporting a pain intensity of $\leq 3 / 10$ in the initial assessment in the PACU (to) and $31.2 \%(n=73)$ reporting a pain intensity of $\geq 7 / 10$ when they arrived at the PACU ( $(0)$. The mean intensity on ward admission at t5 was $2.8 / 10$, with $70.9 \%$ ( $n=166)$ of the patients reporting a pain intensity of $\leq 3 / 10$ in the final assessment in the hospital ward 
(t7), and $5.5 \%(\mathrm{n}=13)$ of the patients reporting a pain intensity of $\geq 7 / 10$ at the end of the first 24 postoperative hours ( $\mathrm{t} 7$ ).

Slope $\mathrm{P} 1$ was positive in $47.8 \%(\mathrm{n}=112)$ of cases. The slopes of the first hour ( $\mathrm{P} 1)$ were in a range between -2.7 and +1.7 . Of the patients who presented a negative slope in $\mathrm{P} 1,40 \%(\mathrm{n}=49)$ also had a negative slope in P2.

The slope was positive in P2 in 48.7\% $(n=114)$ of the patients. Overall, the slopes of the trajectories showed a negative trend over time $(\mathrm{P} 1=-0.25 ; \mathrm{P} 2=$ -0.19) (Figures 1,2). When comparing the slopes of $\mathrm{P} 1$ and $\mathrm{P} 2$, a negative correlation of $\mathrm{rS}=-0.126$ was found $(p=0.056)$.

The slopes of the first 24 postoperative hours (P2) fluctuated between -3.5 and +3.5 , with a proportion of negative slopes of $39.7 \%$. The proportion of positive slopes was identical at $26.5 \%$ in both follow-up periods.

When slopes P1 and P2 were compared, a negative correlation of $r S=-0.126$ was found $(p=0.056)$.

TABLE 1. DEMOGRAPHIC AND CLINICAL CHARACTERISTICS OF PARTICIPANTS

\begin{tabular}{|c|c|}
\hline Characteristics & $n(\%)$ \\
\hline Patients & $234(100)$ \\
\hline \multicolumn{2}{|l|}{ Sex } \\
\hline Women & $96(41)$ \\
\hline Men & $138(59)$ \\
\hline \multicolumn{2}{|l|}{ Age } \\
\hline $18-50$ & $116(49.6)$ \\
\hline $51-70$ & $91(38.9)$ \\
\hline $71-80$ & $21(9)$ \\
\hline 80 & $6(2.6)$ \\
\hline \multicolumn{2}{|l|}{ ASA status } \\
\hline 1 & $36(15.38)$ \\
\hline 2 & $110(47)$ \\
\hline 3 & $87(37.2)$ \\
\hline 4 & $1(0.42)$ \\
\hline \multicolumn{2}{|l|}{ Type of surgery } \\
\hline General & $98(41.9)$ \\
\hline Head and neck & $43(18.4)$ \\
\hline Urology and Gynecology & $40(17.1)$ \\
\hline Orthopedics & $17(7.3)$ \\
\hline Others & $10(4.3)$ \\
\hline Plastic & $8(3.4)$ \\
\hline Thoracic & $7(3.0)$ \\
\hline Neurosurgery & $5(2.1)$ \\
\hline Vascular & $6(2.6)$ \\
\hline
\end{tabular}

ASA (American Society of Anesthesiologists)
Those patients who developed positive slopes during the first hour had an average consumption of morphine equivalent to $6.6 \mathrm{mg}(\mathrm{SD} \pm 6.6)$ during the first 24 hours after the surgery, while those with neutral or negative slopes during the first hour presented an average consumption of $7.1 \mathrm{mg}(\mathrm{SD} \pm 7.6$ ). The opioids used after surgery were hydromorphone (77\%), morphine (17\%) and fentanyl (6\%) (Table 1). Those patients with negative trajectories in P2 had an average morphine consumption of $7.0 \pm 7.0 \mathrm{mg}$ (SD), while the consumption of patients with positive or neutral slopes was $6.9 \mathrm{mg}(\mathrm{SD} \pm 7.6)$. It was not possible to establish a correlation between the consumption of opioids during the first 24 hours and the intensity of pain or their slopes.

\section{DISCUSSION}

A large interindividual variation was found in very early postoperative pain intensity after uncomplicated surgery, emphasizing the need for postop-

FIGURE 1. PAIN TRAJECTORY WHILE IN THE RECOVERY ROOM

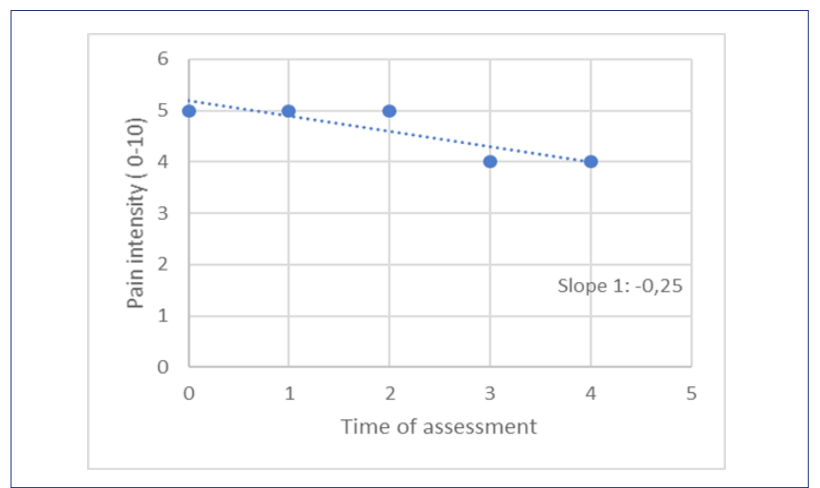

$\mathrm{t} 0=$ on arrival, $\mathrm{t} 1=15 \mathrm{~min}, \mathrm{t} 2=30 \mathrm{~min}, \mathrm{t} 3=45 \mathrm{~min}, \mathrm{t} 4=60 \mathrm{~min}$

FIGURE 2. PAIN TRAJECTORIES DURING THE HOSPITAL STAY.

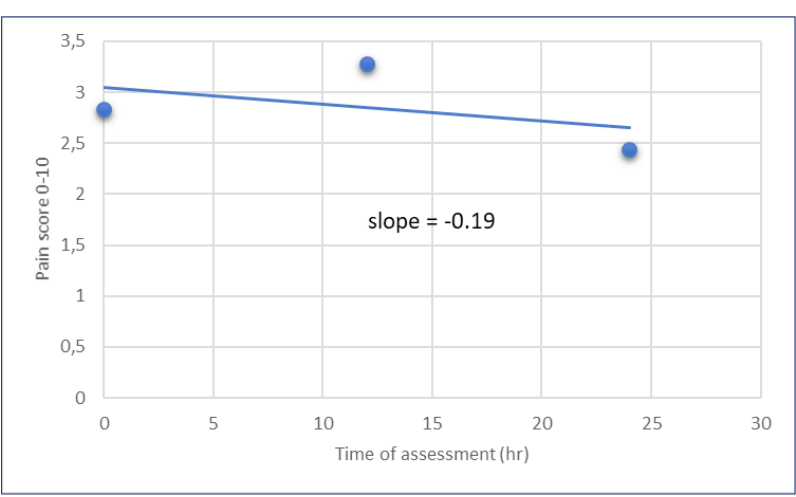


erative pain protocols. This study showed that only four out of every 10 patients had received adequate pain relief when they arrived at the PACU; moreover, a third of the patients arrived at the PACU with unbearable pain. This is in line with earlier findings ${ }^{10,11}$. Undoubtedly many factors contribute to the initial high intensity of pain, depending on the nature of the surgery and sociodemographic factors, but transitional analgesia (from the operating theatre to the PACU) certainly has a significant role in this first outcome. To obtain a complete overview of individual pain behavior during this initial period, the need for triage of analgesia is obvious, after the evaluation of vital signs and at the end of the stay in the PACU. The result of this initial high pain score (intercept in the trajectory path) was a higher number of patients with uncontrolled pain scores for longer during their stay in the PACU.

In contrast, the number of patients with proper pain control at the end of the observation period (first 24 hours) was clearly higher (70.9\%). Also, it was found that when the initial assessment of pain is higher, the slope tends to be more negative (more rapid pain reduction); this was also found in a sample of medical and surgical patients who obtained relief within the first two hours of treatment ${ }^{12}$. Overall there was a decline in pain intensity over time, which is in line with previous results; however, there was wide individual variability ${ }^{13}$. An adequate trajectory of pain implies a low initial intensity and a progressive decrease over time, that is, a negative slope. It is necessary to have professional education and institutional pain policies to implement evidence-based protocols of multimodal analgesia seeking to reduce the number of patients with uncontrolled pain at admission to the $\mathrm{PACU}^{14}$. The usual clinical practice of Acute Pain teams includes an assessment of pain intensity at rest and during activity, after which therapeutic decisions are made such as changes in multimodal analgesic schemes; in those scenarios, one clinical challenge is to translate a subjective assessment of the patient's pain experience into an objective assessment ${ }^{15}$, which is required for proper prescriptions. The trajectory of pain is an instrument that allows pain to be characterized individually and makes it easier to establish the effectiveness of analgesic treatment over time. As described by Chapman et al. ${ }^{9}$, the trajectories of pain enable healthcare professionals to obtain more precise information regarding the ef- fectiveness of analgesic plans, according to whether the slopes of trajectories are positive, neutral, or negative (bad, null, or good levels of effectiveness, respectively). This approach allows professionals to make better decisions in considering pain as a process over time. The expected trajectory of pain in response to treatment is a negative slope, and the lower the intercept, the easier the pain control. However, a neutral slope can be accepted in cases of controlled pain, with lower pain scores (VRS $\leq$ 3/10). The identification of patients with positive slopes (uncontrolled pain), or with neutral slopes, suggests the need for a more efficient treatment. By comparing the proportion of remaining neutral or positive slopes during the entire follow-up period, we find a frequency that is two times greater $(60.2 \%$ vs. $37 \%)$ than that reported by Chapman et al. ${ }^{9}$ In our study, it was not possible to demonstrate a correlation between $\mathrm{P} 1$ and $\mathrm{P} 2$, given that the coefficients were very close to zero and there was no statistical significance. This finding does not lead to the conclusion that there is an association between the trajectory of pain in the first hour and during the first 24 hours.

It is also interesting to note that the amount of morphine used in patients with controlled or uncontrolled pain was nearly the same. Although it has been shown that the amount of opioids used is not directly related to pain scores ${ }^{16,17}$, the contemporary practice is to titrate the doses of analgesics according to the analgesic response obtained. It could be speculated that if the clinicians who attended these patients had information regarding their pain trajectory, they could have made different decisions, such as increasing the doses. Although measuring pain is desirable in all patients, some subgroups may benefit more from obtaining postoperative pain trajectories, i.e., patients with an elevated risk of cardiorespiratory complications, in whom analgesia can modify the prognosis (e.g., coronary disease, morbid obesity, chronic lung diseases, drug addiction, tolerance to opioids, among others).

The limitations of our study are the small sample size, the lack of functional outcomes of the patients and the heterogeneity of surgical interventions; however, the purpose of the study was to demonstrate the usefulness of the method of constructing trajectories, which was accomplished despite the wide variation in procedures. 


\section{CONCLUSIONS}

Uncontrolled postoperative pain is a highly frequent condition. One of the keys to adequate pain control is to reassess the patient's postoperative pain intensity and accordingly determine his/her analgesic needs. The pain trajectory is a dynamic way to accomplish this goal.

\section{Conflict of interest}

The author has declared no conflict of interest.

\section{Compliance with Ethics Requirements}

This article does not contain any studies with human or animal subjects.

\section{RESUMO}

INTRODUÇão: A avaliação da dor pós-operatória aguda é obrigatória para tratamentos eficientes. As trajetórias da dor podem ajudar os profissionais a melhorar os tratamentos. Tem sido sugerido que a falta de controle da dor no período pós-operatório imediato vai gerar maior intensidade dessa dor durante os dias seguintes de estadia no hospital.

OBJETIVO: Determinar o relacionamento entre a dor durante a primeira hora pós-operatória e as 24 horas após a mesma.

MÉTODOS: Lugar da pesquisa: Hospital universitário geral. Desenho do estudo: Foi feito um estudo analítico prospectivo operacional com pacientes submetidos a procedimentos cirúrgicos sob anestesia geral e que foram hospitalizados pelo menos 24 horas antes. Cinco avaliações de dor foram feitas na primeira hora na sala de recuperação, seguidas de três avaliações durante as primeiras 24 horas. Os declives das trajetórias da dor foram calculados e seu relacionamento entre elas foi analisado.

RESULTADOS: Duzentos e trinta e quatro pacientes foram recrutados, 31,3\% apresentaram dor não controlada no ingresso à sala de recuperação; no final das primeiras 24 horas após a cirurgia, 5,5\% dos pacientes apresentaram dor não controlada. O score da primeira intensidade de dor na sala de recuperação teve uma correlação negativa com o declive da primeira hora (P1): $r S=-0,657(p=0,000)$. De maneira similar, o score na primeira intensidade de dor teve uma associação negativa com o declive da trajetória da dor durante a permanência no hospital (P2): rS = -0,141 ( $p=0,032)$. Quando comparados os dois declives, não foi encontrada uma correlação significativa: $r S=-0,126$.

CONCLUSÃO: A trajetória da dor durante a primeira hora não prediz o comportamento da trajetória durante o primeiro dia após a cirurgia. PALAVRAS-CHAVE: Dor pós-operatória. Medição da dor. Manejo da dor. Dor aguda.

\section{REFERENCES}

1. Mwaka G, Thikra S, Mung'ayi V. The prevalence of postoperative pain in the first 48 hours following day surgery at a tertiary hospital in Nairobi. Afr Health Sci. 2013;13(3):768-76.

2. Guay J, Johnson RL, Kopp S. Nerve blocks or no nerve blocks for pain control after elective hip replacement (arthroplasty) surgery in adults. Cochrane Database Syst Rev. 2017;10:CD011608.

3. Ladds E, Redgrave N, Hotton M, Lamyman M. Systematic review: predicting adverse psychological outcomes after hand trauma. I Hand Ther. 2017;30(4):407-19.

4. Anwar S, O'Brien B. The role of intraoperative interventions to minimise chronic postsurgical pain. Br J Pain. 2017;11(4):186-91.

5. Trowbridge ER, Dreisbach CN, Sarosiek BM, Dunbar CP, Evans SL, Hahn $L A$, et al. Review of enhanced recovery programs in benign gynecologic surgery. Int Urogynecol J. 2018;29(1):3-11.

6. Chou R, Gordon DB, Leon-Casasola OA, Rosenberg JM, Bickler S, Brennan $T$, et al. Management of postoperative pain: a clinical practice guideline from the American Pain Society, the American Society of Regional Anesthesia and Pain Medicine, and the American Society of Anesthesiologists' Committee on Regional Anesthesia, Executive Committee, and Administrative Council. | Pain. 2016;17(2):131-57.

7. Boselli E, Bouvet L, Bégou G, Dabouz R, Davidson J, Deloste JY, et al. Prediction of immediate postoperative pain using the analgesia/nociception index: a prospective observational study. Br J Anaesth. 2014;112(4):715-21.

8. Hernández C, Díaz-Heredia J, Berraquero ML, Crespo P, Loza E, Ruiz Ibán MÁ. Pre-operative predictive factors of post-operative pain in patients with hip or knee arthroplasty: a systematic review. 2015;11(6):361-80
9. Chapman CR, Davis |, Donaldson GW, Naylor |, Winchester D. Postoperative pain trajectories in chronic pain patients undergoing surgery: the effects of chronic opioid pharmacotherapy on acute pain. I Pain. 2011;12(12):1240-6.

10. Gan TJ. Poorly controlled postoperative pain : prevalence, consequences, and prevention. J Pain Res. 2017;10:2287-98.

11. Hoofwijk DMN, Fiddelers A, Peters ML, Stessel B, Kessels AGH, Joosten $E$, et al. Prevalence and predictive factors of chronic postsurgical pain and poor global recovery one year after outpatient surgery. Clin J Pain [Internet]. 2015;31(12):1017-25.

12. Kannampallil T, Galanter WL, Falck S, Gaunt MI, Gibbons RD, McNutt $\mathrm{R}$, et al. Characterizing the pain score trajectories of hospitalized adult medical and surgical patients: a retrospective cohort study. Pain. 2016;157(12):2739-46.

13. Chapman CR, Zaslansky R, Donaldson GW, Shinfeld A. Postoperative pain trajectories in cardiac surgery patients. Pain Res Treat. 2012;2012:608359.

14. Katz J, Seltzer Z. Transition from acute to chronic postsurgical pain: risk factors and protective factors. Expert Rev Neurother. 2009;9(5):723-44.

15. A JLAS, Ahmed NN, Islam MRMR, Hossain MMA, Meah MBB, Hossain MMA, et al. The case of tomato in ghana: processing. Eur J Hortic Sci [Internet]. 2017;5(2):1-14.

16. van Dijk JF, Kappen TH, Schuurmans MJ, van Wijck AJ. The relation between patients' NRS pain scores and their desire for additional opioids after surgery. Pain Pract. 2015;15(7):604-9.

17. Gerbershagen HJ, Pogatzki-Zahn E, Aduckathil S, Peelen LM, Kappen TH, van Wijck AJ, et al. Procedure-specific risk factor analysis for the development of severe postoperative pain. Anesthesiology. 2014;120(5):1237-45. 